\title{
Kinetic and thermodynamic analysis of ultra-high pressure and heat-induced denaturation of bovine serum albumin by surface plasmon resonance
}

\author{
Wei Wang*, Yepei Zhu, Tianhao Chen and Guanghong Zhou \\ National Center of Meat Quality and Safety Control/Key Laboratory of Animal Products Processing, Ministry of \\ Agriculture/Synergetic Innovation Center of Food Safety and Nutrition, Nanjing Agricultural University, Nanjing, China \\ *For correspondence: Email: wangwei821220@njau.edu.cn; Tel/Fax: +86-025-84395650
}

Sent for review: 2 March 2017

Revised accepted: 14 July 2017

\begin{abstract}
Purpose: To undertake comparative kinetic and thermodynamic analyses of the interaction of bovine serum albumin (BSA) with IgG pre-treated with ultra-high pressure (UHP) and moderate heat.

Methods: BSA solutions were processed at $100-600 \mathrm{MPa}$ and $25-40{ }^{\circ} \mathrm{C}$. We applied an optical biosensor based on surface plasmon resonance (SPR). The dissociation and association kinetics of antigen-antibody complexes were measured at different temperatures. By analyzing the resultant sensograms, the association rate constant ( $k a)$, dissociation rate constant ( $k d)$, equilibrium dissociation constant (KD), and thermodynamic parameters were calculated.

Results: The equilibrium disassociation constant, $K D$, ranged from a low value of $3.15 \times 10^{-7} \mathrm{M}(0.1$ $\left.\mathrm{MPa}, 25^{\circ} \mathrm{C}\right)$ to a high value of $66.42 \times 10^{-7} \mathrm{M}\left(600 \mathrm{MPa}, 55^{\circ} \mathrm{C}\right)$. Increase in pressure and temperature led to decrease in the affinity of BSA for lgG. Pressure levels above $300 \mathrm{MPa}$ promoted interactions between breakage of disulfide bonds, and the unfolding and aggregation of BSA.

Conclusions: These results show that the combination of UHP and moderate heat treatment cdecrease the allergenicity of BSA by changing their protein conformation.
\end{abstract}

Keywords: Ultra - high pressure, Bovine serum albumin, Surface plasmon resonance, Kinetics, Thermodynamics, Allergens

Tropical Journal of Pharmaceutical Research is indexed by Science Citation Index (SciSearch), Scopus, International Pharmaceutical Abstract, Chemical Abstracts, Embase, Index Copernicus, EBSCO, African Index Medicus, JournalSeek, Journal Citation Reports/Science Edition, Directory of Open Access Journals (DOAJ), African Journal Online, Bioline International, Open-J-Gate and Pharmacy Abstracts

\section{INTRODUCTION}

Food allergies have become increasingly prevalent and occur especially in infants or children [1]. Approximately $1-2 \%$ of infants and $8 \%$ of children suffer from food allergies [2]. Meat and meat products are particularly important foods due to nutritional and functional properties. It has been reported that allergy to meat is rare; positive skin prick tests to beef were described in only $7.69 \%$ of children with atopic dermatitis [3,4]. However, BSA has been identified as one of the most important allergens in bovine meat, with a high degree of cross- reactions due to the significant sequence and structural similarities of serum albumin from different organisms $[5,6]$. In recent years, ultrahigh pressure (UHP) has been more frequently applied instead of traditional thermal treatment, especially for pasteurization [7]. UHP technology has negligible effects on small nutrients, preserving the nutritional and gustatorial properties. Previous research have reported the influence of high pressure on the allergenicity of beef extracts. It has been discovered that the structural changes induced by pressure may reduce or eliminate the antigencity of BSA and pig serum albumin (PSA) [8]. However, there are 
a few papers published on kinetic and thermodynamic changes in the binding properties of BSA treated by UHP.

Surface plasmon resonance (SPR) is a resonant charge density oscillation, which arises at the surface of a metallic film when light is reflected at the film under specific conditions. SPR could measure extremely small variations in mass on the metal surface due to interactions between a receptor on the metal and its target molecule. Thus, a receptor such as an antibody could be immobilized on the surface of the metal. Compared with other techniques, SPR technology permits a label-free and real-time analysis [9,10]. Recently, SPR was widely used in the study of interactions of various biological molecules, ranging from proteins, oligonucleotides and lipids, to small particles [11]. In the field of allergies, SPR has been applied to detect specific antibodies, to measure their binding affinities to their allergens, and to estimate enthalpy and entropy changes in antigen-antibody complex formation [12,13].

The main goal of the present study consisted of comparative kinetic and thermodynamic analyses of the interaction of BSA with IgG pre-treated with UHP and moderate heat. For this purpose, we applied an optical biosensor, Biacore ${ }^{\mathrm{TM}}$ T200 [13], based on SPR. The dissociation and association kinetics of antigen-antibody complexes were measured at different temperatures. By analyzing the resultant sensograms, the association rate constant $\left(k_{\mathrm{a}}\right)$, dissociation rate constant $\left(k_{d}\right)$, equilibrium dissociation constant $\left(K_{\mathrm{D}}\right)$, and thermodynamic parameters were calculated. Some researchers have reported that UHP treatment induces changes in tertiary structure. The secondary structure has always been shown to experience no significant change. Thus, structural changes in BSA after the application of pressure and moderate heat treatments were also assessed in order to determine the changes in free sulfhydryl (SH) contents.

\section{EXPERIMENTAL}

\section{Reagents}

BSA was obtained from Sigma-Aldrich (St Louis, MO, USA). Anti-BSA mouse monoclonal-lgG was provided by the College of Food Science and Technology at Nanjing Agricultural University (Nanjing, China) [14]. Carboxymethylated dextran CM5 sensor chip was purchased from GE Healthcare (Pittsburgh, PA, USA). The following buffers were solutions and reagents for the optical biosensor Biacore ${ }^{\mathrm{TM}}$ T200: PBST (137
$\mathrm{mM} \mathrm{NaCl}, 2.7 \mathrm{mM} \mathrm{KCl}, 10 \mathrm{mM} \mathrm{Na} \mathrm{HPO}_{4}, 1.8$ $\mathrm{mM} \mathrm{KH} \mathrm{PO}_{4}, 0.05 \%$ (v/v) Tween 20, $30 \mu \mathrm{L} / \mathrm{min}$, $\mathrm{pH} \quad 7.4$; amine coupling reagents: 1-(3dimethylpropyl)-3-ethylcarbodiimide (EDC), Nhydroxysuccinimide (NHS); regenerative reagent: $10 \mathrm{mM}$ glycine- $\mathrm{HCl}, \mathrm{pH} 2.1$; blocking agent: hydrochloric acid ethanolamine (1 M, pH 8.5); PBS ( $\mathrm{pH} 7.4)$; recovery reagent solution: $\mathrm{Gly}-\mathrm{HCl}$ (10 mM, pH 2.1, $30 \mathrm{~s}$ ).

\section{UHP treatment}

A high-pressure machine unit (model S-FL8509W, Stansted Fluid Power, Stansted, UK) with chamber dimension of $300 \mathrm{~mm}$ height and 37 $\mathrm{mm}$ diameter was used in the experiments involving UHP treatment. The system can be operated over a pressure range from $0 \mathrm{MPa}$ to $900 \mathrm{MPa}$ under controlled temperature conditions $\left(20-100{ }^{\circ} \mathrm{C}\right)$. Prior to the UHP treatment, BSA was dissolved in PBS ( $\mathrm{pH} 7.4$ ) and was $5 \%(w / v)$ in the polyethylene bags. Samples were subjected to UHP treatment at $100,200,300,400,500$, and $600 \mathrm{MPa}$ for 10 min, and the temperature was separately stabilized at 25,40 , and $55^{\circ} \mathrm{C}$ during UHP treatment. After UHP treatment, the BSA solution was removed from the vessel and immediately cooled in an ice bath. Unpressurized samples served as the experimental control group.

\section{Surface modification of SPR chip}

Acidic piranha solution $\left(\mathrm{H}_{2} \mathrm{O}_{2}: \mathrm{H}_{2} \mathrm{SO}_{4}\right.$ in a $1: 3$ ratio) was applied to clean the SPR surface. After rinsing with pure water, the chip was washed three times with absolute ethanol and then dried in a vacuum oven. The surface of the chip, used for immobilization, was chemically modified by reaction with a $3: 1 \mathrm{v} / \mathrm{v}$ ratio of a mixture of EDC and NHS (15 $\mu \mathrm{L} / \mathrm{min}, 420 \mathrm{~s})$. Goat anti-mouse $\lg \mathrm{G}(100 \mu \mathrm{g} / \mathrm{mL}$ in PBS, $\mathrm{pH} 5.0,420 \mathrm{~s})$ was immobilized on a separately designated sensor surface by amine coupling at $25^{\circ} \mathrm{C}$. Following deactivation, hydroxyethylammonium chloride (1 $\mathrm{mol} / \mathrm{L}, 25 \mu \mathrm{L} / \mathrm{min}, 360 \mathrm{~s})$ was applied to remove the unreacted activated groups. The chip was stabilized by washings with PBST buffer to remove excess antibody adsorbed on the chip.

\section{SPR-based assays and binding kinetics of BSA}

Binding kinetics and affinity assays were determined at different temperatures based on the Biacore ${ }^{\mathrm{TM}}$ T200 biosensor (GE Healthcare, Uppsala, Sweden). The BSA solution, at different concentrations, was injected after the surface was equilibrated by injection of blank buffer. Time-dependent binding curves were 
simultaneously monitored. The limit of detection $(L O D)$ was calculated using Eq 1.

$L O D=3.3 \mathrm{~S} / \mathrm{m}$

where $S$ is the standard deviation of the intercept and $m$ is the slope of the regression line [15].

Affinity constants were measured by Biacore ${ }^{\mathrm{TM}}$ T200, and a 1:1 Langmuir binding model was applied to the resulting graphs. Association and dissociation curves were fitted globally. The rate of complex formation during analyte injection was calculated according to Eq 2.

$d R / d t=k_{a} C\left(R_{\max } R\right)-k_{d} R(1: 1$ interaction $)$ (2)

where $R$ is the SPR signal in response units (RU), $C$ is the analyte concentration, $R_{\max }$ is the maximum analyte binding capacity in $R U$, and $d R / d t$ is the rate of SPR signal change.

Multiple curves indicate the different concentrations of the protein antigen used to obtain the equilibrium dissociation constant. $k_{\mathrm{a}}$ and $k_{\mathrm{d}}$ were measured according to the RU differences between flow buffer and injected sample buffer. The equilibrium disassociation constant was defined as $K_{\mathrm{D}}$; where $K_{\mathrm{D}}=k_{\mathrm{d}} / k_{\mathrm{a}}$.

\section{Determination of thermodynamic parameters by SPR}

The interaction between the immobilized antimouse IgG and BSA samples was examined using biosensor analysis at different pressures. Analyte solutions were obtained by serial dilutions under a buffer stream (PBST, $\mathrm{pH}$ 7.4). To regenerate the surface, Gly- $\mathrm{HCl}(10 \mathrm{mM}, \mathrm{pH}$ $2.1,30 \mathrm{~s})$ was injected between each analyte injection. The Gibbs free energy changes ( $\Delta G$ ) were calculated by the $K_{D}$ values according to $\mathrm{Eq}$ 3.

$\Delta \mathrm{G}=-R \ln K_{D}$

where $T$ is absolute temperature, $R$ is the universal gas constant, and $K_{D}$ is the equilibrium dissociation constant of the antibody-BSA complex.

The values of enthalpy change, $\Delta H$, and entropy change, $\Delta S$ were measured by Van't Hoff equation ( $\mathrm{Eq} 4$ ). The different values of $K_{D}$ at different temperatures were applied to obtain the Gibbs free energy (G) versus temperature plots. $\Delta H$ and $\Delta S$ values were obtained from the slope and y-intercept, respectively.
$\Delta \mathrm{G}=\Delta \mathrm{H}-\mathrm{T} \Delta \mathrm{S}$

\section{Free sulfhydryl (SH) determination}

Determination of SH used a modified Ellman's method and 5, 5'-dithiobis-2-nitrobenzoic acid (DTNB) [16].

The samples were diluted with $20 \mathrm{mM}$ PBS buffer $(\mathrm{pH} \mathrm{7.4)}$ to reach $2.5 \mathrm{mg} / \mathrm{mL}$ of BSA, and $40 \mu \mathrm{L}$ of $10 \mathrm{mM}$ DTNB solution (in $0.09 \mathrm{M}$ Gly, 0.004 M EDTA, PBS buffer, $\mathrm{pH}$ 8.0) was added into $4 \mathrm{~mL}$ of the sample and reacted for $5 \mathrm{~min}$ at $25^{\circ} \mathrm{C}$. The absorbance at $412 \mathrm{~nm}$ was measured in a microplate reader (SpectraMax M2, Molecular Devices LLC, Sunnyvale, USA). The PBS buffer ( $\mathrm{pH} 7.4$ ) was used as blank. Each sample was measured in triplicate. Free $\mathrm{SH}$ groups were evaluated according to Eq 5.

$S H(\mu m o L / g)=73.53 \times A_{412} \times D / C$

where $A_{412}$ is the absorbance at $412 \mathrm{~nm}, C$ is the sample concentration, and $D$ is the dilution factor.

\section{Statistics}

Statistical analysis were performed using SPSS software (SPSS $15.0 \mathrm{~K}$, Chicago, IL, USA). All data were expressed as the mean \pm standard error of the mean. Comparisons of mean values were performed by one-way ANOVA. Significant difference was determined at the 0.05 probability level.

\section{RESULTS}

\section{Coupling}

Antibodies (100 $\mu \mathrm{g} / \mathrm{mL}$ ) were directly immobilized on a CM5 sensor chip using a standard amine coupling protocol to a level of $18000 \mathrm{RU}$. The coupling curve is shown in Figure 1.

\section{Linearity range}

Figure 2A shows the effect of BSA concentration on the SPR response of the BSA sensor. BSA samples $(5 \mathrm{mg} / \mathrm{mL}, \mathrm{pH} 7.4)$ were dissolved in PBS buffer ( $\mathrm{pH} 7.4)$ to concentrations ranging from 0.5 to $222 \mathrm{nM}$. These were then used to generate a curve in order to get the lowest working concentrations of BSA in the PBS buffer.

A typical dose-response curve and sensogram at the different concentration gradients of BSA is illustrated in Figure 2A. The initial binding rate depended on the concentration and flow rate of BSA. As shown in Figure 2B, the SPR sensor 
signal increased linearly with the concentration of BSA. The SPR responses were linearly correlated with the concentration of BSA. The regression equation obtained is shown in Eq 6.

$Y=0.10462 x+8.01897\left(R^{2}=0.99759\right)$ (6)
The $L O D$ value for BSA was $1.6 \mathrm{nM}$. Since the analyte concentrations range between $20 \%$ and $80 \%$ of ligand saturation, or $0.1-10$ times the $K_{\mathrm{D}}$, the analyte concentrations should range from $30-66,000 \mathrm{nM}$. In this study, binding affinity was determined at the concentrations of $0.156,0.312$, $0.625,1.2,2.5$ and $5 \mu \mathrm{M}$.

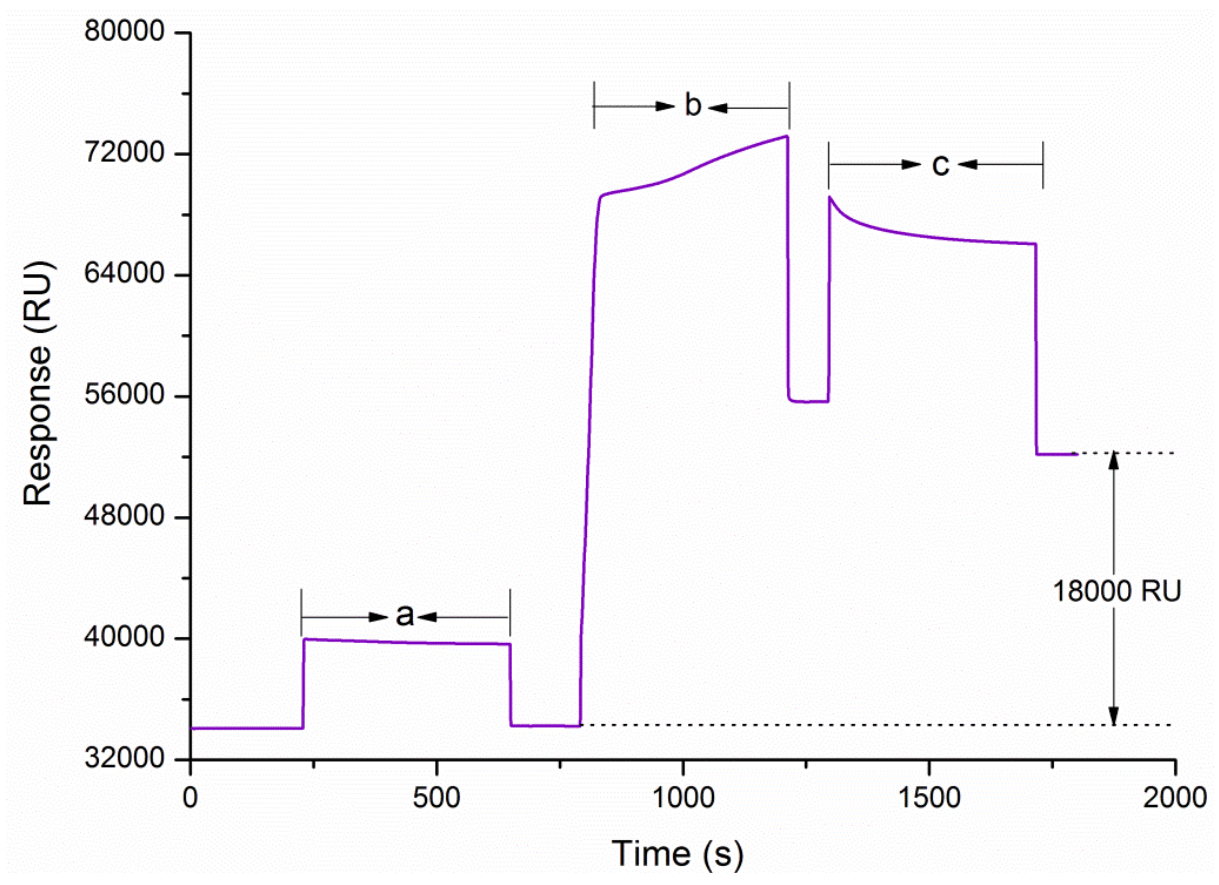

Figure 1: A typical SPR sensorgram curve of the activate-couple. a) Activation: The carboxylic group layer on the chip surface was activated as described in Materials and Methods. b) Coupling: $100 \mu \mathrm{L}$ of antibody solution (100 $\mu \mathrm{g} / \mathrm{mL}, \mathrm{pH} 7.0$ ) was introduced into the activated sensor chip for immobilization of goat anti-mouse lgG on the chip surface. c) Sealing: Non-reacted carboxylic groups on the chip surface were deactivated by introducing a 1 M 2-aminoethanol solution on the chip surface to control nonspecific adsorption

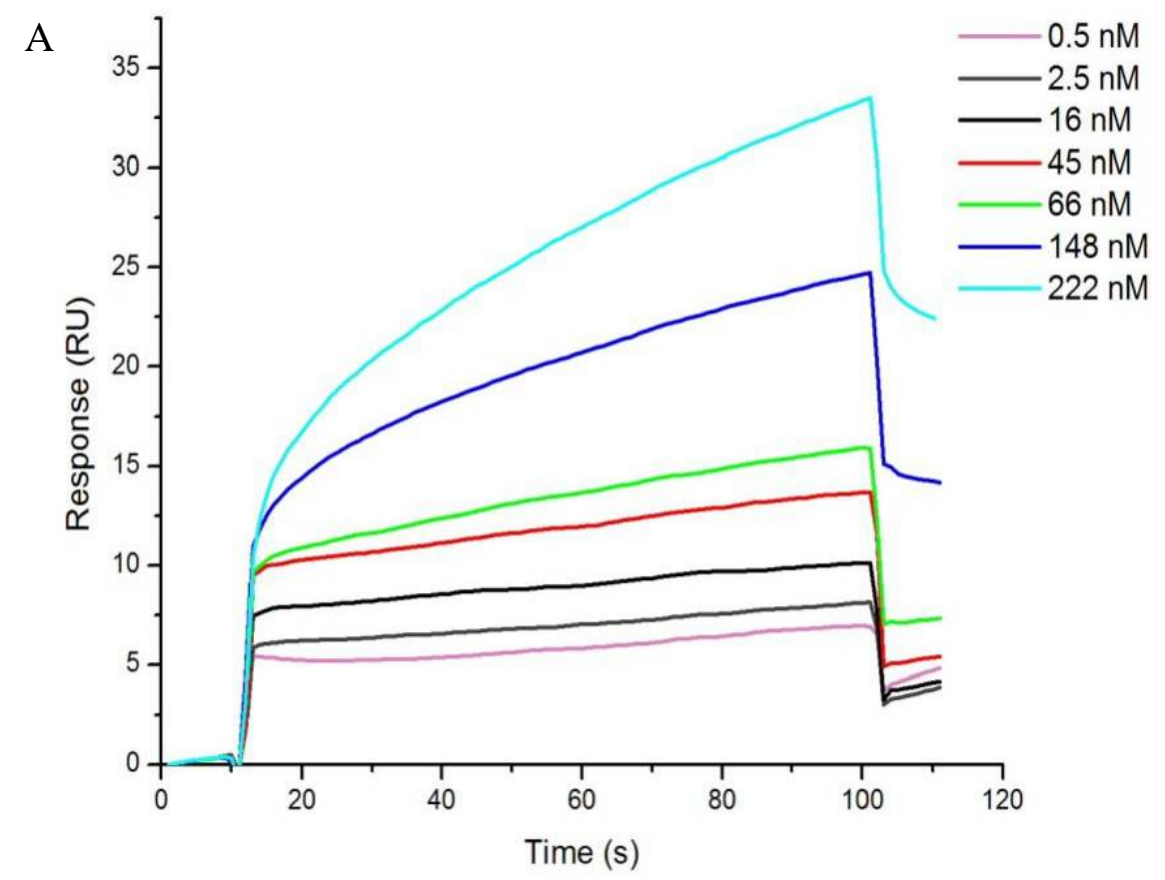

Figure 2: (A) Effect of BSA concentration on the SPR response of the BSA sensor 
Association and dissociation constants, and affinity

Table 1 provides $K_{\mathrm{D}}$ as determined by measurements of different samples using the SPR sensor. The values of $K_{\mathrm{D}}$ ranged from 3.37 $\times 10^{-7} \mathrm{M}\left(100 \mathrm{MPa}, 25^{\circ} \mathrm{C}\right)$ to a maximum value of $66.42 \times 10^{-7} \mathrm{M}\left(600 \mathrm{MPa}, 55^{\circ} \mathrm{C}\right)$. The results showed that the observed decrease in affinity was attained by a decrease in $k_{\mathrm{a}}$ and an increase in $k_{\mathrm{d}}$. The decrease in $k_{\mathrm{a}}$ provided a negative effect on the affinity. On the other hand, the decrease in $k_{\mathrm{d}}$ was positive. The lowest $k_{\mathrm{a}}$ and the highest $k_{d}$ suggested that the interaction of the sample $\left(600 \mathrm{MPa}, 55^{\circ} \mathrm{C}\right)$ with $\mathrm{IgG}$ was the lowest in affinity. In the affinity measurement of antibody-antigen interaction, it is often advantageous to have a high $k_{\mathrm{d}}$, manifested as an index of short residency time on the receptor (residency time $=1 / k_{d}$ ).

\section{Thermodynamic data}

The analyte protein (BSA) interacted with the ligand IgG by non-covalent bonds such as Van der Waals forces, electrostatic interactions and hydrophobic interactions [17]. During the binding process, hydrogen bonds between the ligand and water molecules were disturbed by the effect of de-solvation. Simultaneously, de-solvation induced reactions between the non-polar groups of the analyte and the ligand [18]. The values of thermodynamic parameters are shown in Figure 3. For all the treated samples, the antibodyantigen binding interactions were driven by enthalpy and entropy. The experimental data suggest that increased pressure induced enthalpy changes from positive to negative. Enthalpy changes were caused by the breakage and formation of hydrogen bonds, Van der Waals interactions and hydrophobic effects [19]. $\Delta \mathrm{H}<0$ indicated that the increase in temperature was negative to the binding process. The thermodynamics results were consistent with dynamic results. It was observed that increases in temperature and pressure led to decreases in values of $\Delta \mathrm{H}$ and $\Delta \mathrm{S}$. Pressure levels of 500 and $600 \mathrm{MPa}$ changed the value of $\Delta S$ from positive to negative.

The total free energy change of the interactions was determined by free energy of association $\left(\Delta G_{\text {ass }}\right)$ and free energy of dissociation $\left(\Delta G_{\text {diss }}\right)$ where $\Delta G=\Delta G_{\text {ass }}-\Delta G_{\text {diss. }}$. Values of $\Delta G_{\text {ass }}$ and $\Delta \mathrm{G}_{\text {diss }}$ were calculated from $k_{\mathrm{a}}$ and $k_{\mathrm{d}}$ at different temperatures. The data showed that significant changes in Gibbs free energy did not occur during complex formation. As shown in Figure 3, the decrease in affinity received a larger contribution from $\Delta \mathrm{H}$ or $\Delta \mathrm{S}$ than from $\Delta \mathrm{G}$ during antigen-antibody binding.

Table 1: $K_{\mathrm{D}}$ values of binding of BSA samples treated at $100-600 \mathrm{MPa}$ at $25-55^{\circ} \mathrm{C}$. Values mean $\pm \operatorname{SEM}(n=3)$

\begin{tabular}{|c|c|c|c|}
\hline Treatment & $K_{\mathrm{D}}\left(\times 10^{-1}, \mathrm{M}\right), 25^{\circ} \mathrm{C}$ & $K_{\mathrm{D}}\left(\times 10^{-1}, \mathrm{M}\right), 40^{\circ} \mathrm{C}$ & $K_{D}\left(\times 10^{-1}, M\right), 55^{\circ} \mathrm{C}$ \\
\hline Control & $3.15 \pm 0.16$ & $3.21 \pm 0.23$ & $3.35 \pm 0.39$ \\
\hline $100 \mathrm{MPa}$ & $3.37 \pm 0.72$ & $3.45 \pm 1.11$ & $3.93 \pm 1.02$ \\
\hline $200 \mathrm{MPa}$ & $3.63 \pm 0.42$ & $4.80 \pm 0.91$ & $4.89 \pm 0.77$ \\
\hline $300 \mathrm{MPa}$ & $3.78 \pm 0.56$ & $7.51 \pm 0.72$ & $9.15 \pm 0.51$ \\
\hline $400 \mathrm{MPa}$ & $4.94 \pm 0.56$ & $9.65 \pm 0.49$ & $9.55 \pm 0.92$ \\
\hline $500 \mathrm{MPa}$ & $6.60 \pm 0.34$ & $10.08 \pm 0.65$ & $21.17 \pm 0.71$ \\
\hline $600 \mathrm{MPa}$ & $9.72 \pm 0.68$ & $14.90 \pm 0.41$ & $66.42 \pm 0.62$ \\
\hline
\end{tabular}

\section{Structural analysis data}

To better understand the kinetic and thermodynamic analyses conducted by SPR, the $\mathrm{SH}$ contents of BSA were determined (Figure 4). The results suggest that the conformational changes induced by pressure $(100-300 \mathrm{MPa})$ on BSA exposed its free $\mathrm{SH}$ groups. However, at pressures above $300 \mathrm{MPa}$, the free $\mathrm{SH}$ groups followed a reverse trend and the content of $\mathrm{SH}$ decreased compared with the control samples $(0.1 \mathrm{MPa})$. A significant amount of free $\mathrm{SH}$ groups in the native globular conformation were masked to attack, due to their location in poorly accessible regions of the folded structure. Therefore, the level of $\mathrm{SH}$ groups could be considered as an indication of protein unfolding or denaturation [20].

\section{DISCUSSION}

The kinetic results showed that as the temperature of measurement increased, the value of the $K_{D}$ decreased, and the affinity of the antibody and BSA decreased. The data also indicated that the increasing pressure and temperature resulted in quicker dissociation and weaker affinity, and that higher pressure and temperature resulted in reduction of BSA allergenicity. Thermodynamic analysis results suggest that the changes in the entropy of the system were negative and adverse to the 


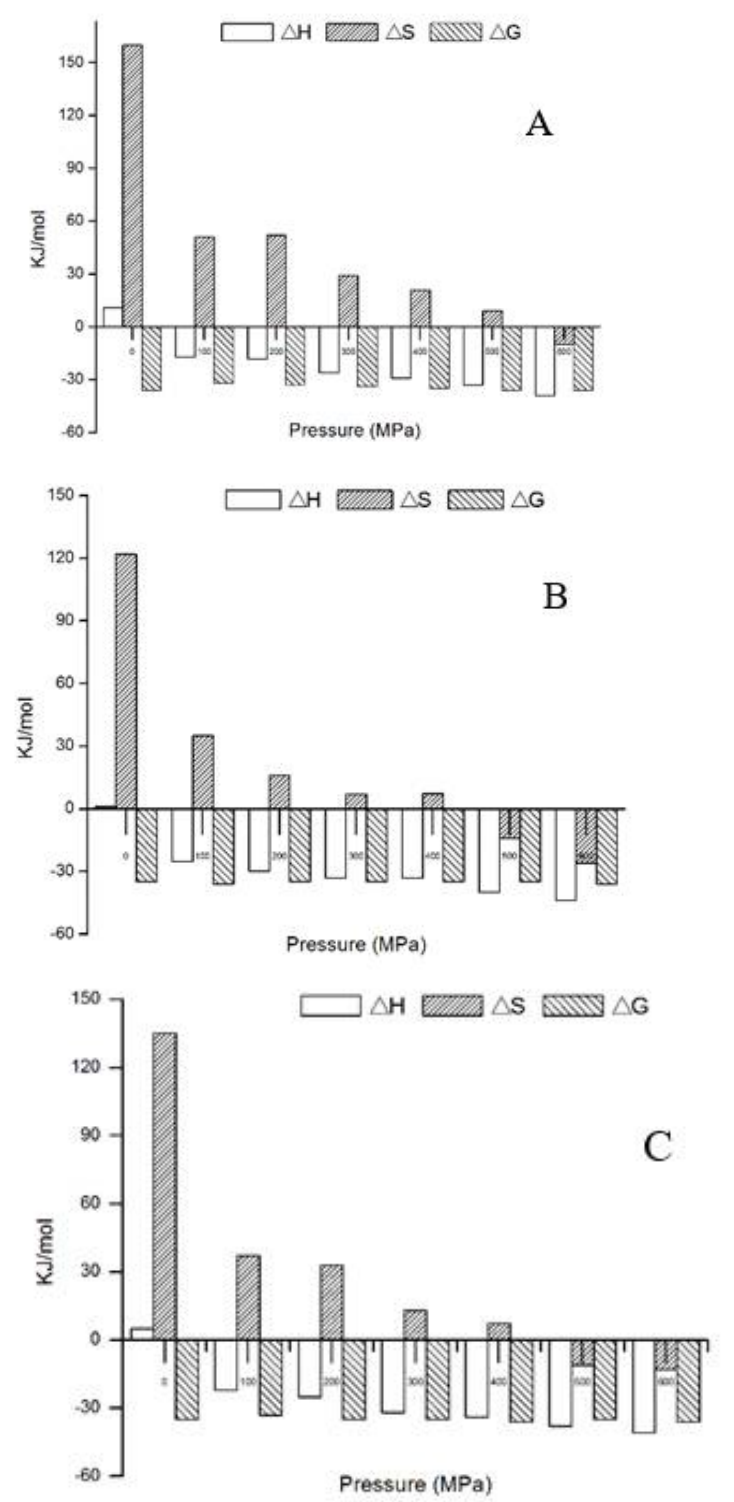

Figure 3: Temperature-dependent thermodynamic profiles for the binding of IgG to BSA subjected to different pressures and temperatures. A: UHP treatment with temperature fixed at $25^{\circ} \mathrm{C}$; B: UHP treatment with temperature fixed at $40^{\circ} \mathrm{C}$; and C: UHP treatment with temperature fixed at $55^{\circ} \mathrm{C}$ ). The pressure of the control was $0.1 \mathrm{MPa}$ section

antigen-antibody interactions, but were conducive for reduction of affinity between the two.

Generally, antigen-antibody interaction is accompanied by a conformational change such as rotation. In this study, entropy changes were obtained mainly from protein-solvent interactions, and from the protein conformational changes after ligand binding. The formation of BSA-lgG complex is actually a process driven by enthalpy and solvent entropy. Similar to most other antigen-antibody interactions, the binding of an antigen is enthalpically driven throughout the physiological temperature range. Structural flexibility of the antigen-antibody site is key to the antigen binding activity [20]. Burgen et al [21] suggested that such a conformational flexibility would result in a faster rate of association and dissociation, a mechanism of recognition tagged the "induced fit" model.

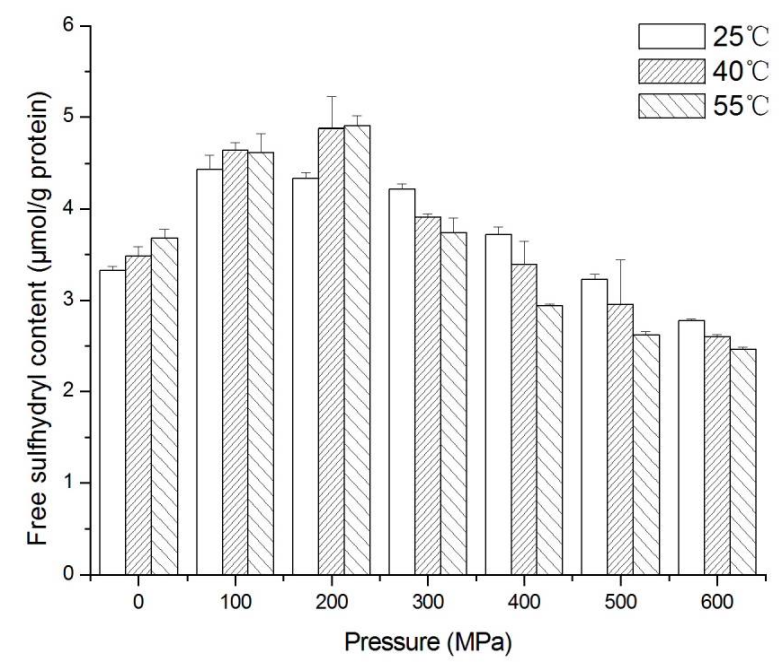

Figure 4: Effect of UHP and heat treatment on the free SH content of BSA (Pressure holding time was 10 $\min )$. The pressure of the control was $0.1 \mathrm{MPa}$

The change of the SH content demonstrated that UHP (at $100-300 \mathrm{MPa}$ ) was able to induce breakage of disulfide bonds in BSA, as well as unfolding of BSA. On the other hand, pressure levels above $300 \mathrm{MPa}$ enhanced protein-protein interactions, as well as transient and long term interactions between neighboring polypeptide side chains [7].

It is known that UHP can induce structural unfolding, precipitation, protein denaturation, and even dissociation of some proteins into subunits. Studies have demonstrated that protein flexibility may play an important role in antigen-antibody recognition and in the biological functions of proteins [22]. The high pressure and moderate temperature treatment might induce stiffness which is thought to be unfavorable for antigenantibody interactions. In addition, the decreased allergenicity of BSA might be attributed to changes in protein conformation caused by high pressure and moderate temperature. Conformational changes such as protein refolding or re-aggregation may actually hide some conformational epitopes or IgG and IgE binding sites so that some allergen activities could be minimized.

\section{CONCLUSION}

The findings of this study highlight the relevance of detailed thermodynamic and kinetic analysis of 
the BSA-lgG interactions using SPR. A reduction in affinity was induced by pressure levels of 100 $-600 \mathrm{MPa}$ in the temperature range of $25-55$ ${ }^{\circ} \mathrm{C}$. Structural analysis showed that UHP caused protein unfolding and/or aggregation. The treatments led to intense protein-protein interactions via the formation of complex aggregates caused by formation of new disulfide bonds. The results also show the potential of UHP for inducing changes in BSA structure and allergenicity. The combination of UHP and moderate heat treatment will not only prevent beef and milk allergies, but could also be applied to produce hypoallergenic beef and milk.

\section{DECLARATIONS}

\section{Acknowledgement}

This work was supported by Natural Science Foundation of Jiangsu Province (no. BK20140722) and National Natural Science Foundation of the People's Republic of China (no. 31501395).

\section{Conflict of Interest}

No conflict of interest associated with this work.

\section{Contribution of Authors}

The authors declare that this work was done by the authors named in this article and all liabilities pertaining to claims relating to the content of this article will be borne by them.

\section{Open Access}

This is an Open Access article that uses a funding model which does not charge readers or their institutions for access and distributed under the terms of the Creative Commons Attribution License (http://creativecommons.org/ licenses/by/ 4.0) and the Budapest Open Access Initiative (http://www.budapestopena ccessinitiative.org/read), which permit unrestricted use, distribution, and reproduction in any medium, provided the original work is properly credited.

\section{REFERENCES}

1. Yamamoto S, Mikami N, Matsuno M. Effects of a highpressure treatment on bovine gamma globulin and its reduction in allergenicity. Biosci Biotechnol Biochem 2010; 74(3): 525-530.

2. Kim KBWR, Lee SY, Song EJ. Effect of heat and autoclave on allergenicity of porcine serum albumin. Food Sci Biotechnol; 2011; 20(2): 455-459.
3. Fiocchi $A$, Restani P, Riva E. Meat allergy: Specific IgE to $B S A$ and OSA in atopic, beef sensitive children. $J$ Am Coll Nutr 1995; 14(3): 239-244.

4. Sampson HA. Role of immediate hypersensitivity in the pathogenesis of atopic dermatitis. $J$ Allergy Clin Immunol 1983; 71(5): 473-480.

5. Restani P, Fiocchi A, Beretta B. Effects of structure modifications on IgE binding properties of serum albumins. Int Arch Allergy Immunol 1998; 117(2): 113119.

6. Wei Y, Qiao L, Gu X. Effect of high pressure treatment on the physicochemical and functional properties of egg yolk. Eur Food Res Technol 2010; 231(3): 371-377.

7. Maria SD, Ferrari G, Maresca P. Effects of high hydrostatic pressure on the conformational structure and the functional properties of bovine serum albumin. Innov Food Sci Emerg 2015; 33: 67-75.

8. Kim KBWR, Lee SY, Song EJ. Changes in allergenicity of porcine serum albumin by gamma irradiation. Korean $J$ Food Sci An 2010; 30(3): 397-402

9. Yanase $Y$, Hiragun $T$, Yanase $T$. Clinical diagnosis of type I allergy by means of SPR imaging with less than a microliter of peripheral blood. Sens Biosensing Res 2014; 2: 43-48.

10. Indyk HE, Gill BD, Woollard DC. An optical biosensorbased immunoassay for the determination of bovine serum albumin in milk and milk products. Int Dairy J 2015; 47: 72-78.

11. Nishijima $H$, Kosaihira A, Shibata J. Development of signaling echo method for cell-based quantitative efficacy evaluation of anti-cancer drugs in apoptosis without drug presence using high-precision surface plasmon resonance sensing. Anal Sci 2010; 26(5): 529534.

12. Chardin H, Mercier K, Frydman C, Vollmer N. Surface Plasmon Resonance imaging: A method to measure the affinity of the antibodies in allergy diagnosis. $J$ Immunol Methods 2014; 405(2): 23-28.

13. Claude N, Hervé L, Langendorf CG. Characterisation of peptide microarrays for studying antibody-antigen binding using surface plasmon resonance imagery. Plos One 2010; 5(8): 12152.

14. Zhu Y P, Wang W, Lü $Q Q$, Teng $S$, Xu XL, Zhou GH. Development of an indirect competitive ELISA for detection of animal allergen bovine serum albumin $J$ Nanjing Agr Uni; 2016; 39(2): 309-311.

15. Yola M L, Atar N, Erdem A. Oxytocin imprinted polymer based surface plasmon resonance sensor and its application to milk sample. Sensor Actuat B-Chem 2015; 221: 842-848.

16. Ellman GL. Tissue sulfhydryl groups. Arch Biochem Biophys 1959; 82: 70-77.

17. Jimenez R, Salazar G, Baldridge KK, Romesberg FE. Flexibility and molecular recognition in the immune system. P Natl Acad Sci USA 2003; 100(1): 92-97.

18. Roque ACA. Ligand-Macromolecular Interactions in Drug Discovery. Clifton, N.J 2010; $p 572$. 
Wang et al

19. Kalyani $M$, Karin $R$, Winse $M$. Thermodynamic and kinetic characterization of hydroxyethylamine $\beta$-secretase-1 inhibitors. Biochem Bioph Res Co 2013; 441(2): 269293.

20. Gevondyan NM, Gevondyan VS, Gavrilyeva EE, Modyanov NN. Analysis of free sulfhydryl groups and disulfide bonds in $\mathrm{Na}+\mathrm{K}+$-ATPase. Febs Letters 1989; 255(2): 265-268.
21. Burgen ASV, Roberts GCK, Feeney J. Binding of flexible ligands to macromolecules. Nature1975; 253(5494): 753-755.

22. Sagawa $T$, Oda $M$, Ishimura $M$. Thermodynamic and kinetic aspects of antibody evolution during the immune response to hapten. Mol Immunol 2003; 39(13): 801808. 